\title{
PENERAPAN METODE K-NEAREST NEIGHBOR UNTUK PREDIKSI PENJUALAN BERBASIS WEB PADA PT.WIKA INDUSTRY ENERGY
}

\author{
Abdul Ghani Muttaqin, Karina Auliasari, Febriana Santi Wahyuni \\ Program Studi Teknik Informatika S1, Fakultas Teknologi Industri \\ Institut Teknologi Nasional Malang, Jalan Raya Karanglo km 2 Malang, Indonesia \\ ghanzsloww@gmail.com
}

\begin{abstract}
ABSTRAK
Pada setiap perusahaan, penjualan merupakan hal yang sangat penting agar perusahaan bisa tetap beroprasi, pada umumnya perusahaan akan menggunakan prediksi atau peramalan pada penjualan produk untuk mengetahui produk apa yang akan lebih banyak terjual pada masa yang akan datang. Untuk melakukan prediksi atau peramalan, PT.WIKA Industri Energy mengumpulkan seluruh data penjualan dari tahun ke tahun. . Dari prediksi menghasilkan suatu data yang menunjukan suatu penjualan produk akan naik dan produk lain akan turun. Namun terdapat satu kasus dimana prediksi ini justri terbalik, dalam artian apabila salah satu produk diprediksi akan naik penjualannya, justru malah terjadi penurunan pada produk tersebut dipreiode yang telah di prediksi.

Maka dari itu dilakukan penelitian untuk membuat program prediksi penjualan berbasis web yang dapat digunakan untuk memprediksi hasil penjualan pada PT.WIKA Industri Energy menggunakan metode $K$-Nearest Neighbor berbasis website dengan tujuan untuk mengetahui sesuatu yang paling mungkin terjadi di masa depan berdasarkan informasi dari masa sebelumnya dan masa sekarang. Prediksi tidak harus memberikan jawaban yang benar-benar akurat melainkan mencari jawaban sedekat mungkin dengan kemungkinan yang akan terjadi dimasa yang akan datang. Metode K-Nearest Neighbor adalah suatu metode yang melakukan klasifikasi terhadap data baru dan mengelompokan data tersebut dengan data lama berdasarkan jarak paling dekat dengan data baru tersebut.

Hasil dari penelitian ini berupa website yang dapat digunakan untuk memprediksi penjualan dengan nilai keakuratan metode yang di uji menggunakan 20 data uji dan 288 data latih diperoleh hasil akurasi program sebesar $95 \%$ dan nilai error sebesar $5 \%$.
\end{abstract}

Kata Kunci : Sistem Prediksi, Implementasi K-NN, Penjualan

\section{PENDAHULUAN}

Pada setiap perusahaan, penjualan merupakan hal yang sangat penting agar perusahaan bisa tetap beroprasi dan mendapatkan penghasilan untuk memproduksi macam-macam produk yang akan dijual. Setiap perusahaan akan bersaing melalui mutu dan kualitas produk agar penjualan bisa tetap naik sesuai yang diharapkan. Perusahaan biasanya akan menggunakan prediksi atau peramalan pada penjualan produk untuk mengetahui produk apa yang akan lebih banyak terjual pada masa yang akan datang. PT.WIKA Industri Energy telah melakukan prediksi penjualan produk hemat energy yang diproduksi dengan melihat statistik data penjualan produk.

Untuk melakukan prediksi atau peramalan, PT.WIKA Industri Energy mengumpulkan seluruh data penjualan dari tahun ke tahun. Dari prediksi menghasilkan suatu data yang menunjukan suatu penjualan produk akan naik dan produk lain akan turun. Namun terdapat satu kasus dimana prediksi ini justri terbalik, dalam artian apabila salah satu produk diprediksi akan naik penjualannya, justru malah terjadi penurunan pada produk tersebut dipreiode yang telah di prediksi, begitupula pada salah satu produk yang diprediksi akan mengalami penurunan penjualan justru mengalami penaikan pada masa periode yang sudah diprediksikan. Hasil prediksi dapat dibilang kurang akurat.

Pada pendahuluan jabarkan permasalahan yang akan anda angkat pada skripsi anda. Jabarkan akar yang menjadi sebab dari permasalahan yang anda angkat, kerugian - kerugian akibat dari permasalah tersebut. Kemukakan dengan rinci urgensi permasalahan tersebut hari diberikan solusi.

Kemukakan solusi yang anda buat untuk mengatasi permasalahan yang anda kemukakan, aplikasi dan metode yang anda buat untuk menyelesaikan permasalahan, keuntungan keuntungan apabila menggunakan aplikasi dan metode yang anda buat.

Secara garis besar, pendahuluan bisa anda ringkas bab 1 dari skripsi yang anda buat.

\section{TINJAUAN PUSTAKA}

\subsection{Penelitian Terkait}

Penjualan produk suatu perusahaan dipengaruhi beberapa faktor, seperti perubahaan jumlah permintaan konsumen, perubahan jumlah penjualan dan adanya pengaruh dan tren pasar. Adanya beberapa faktor tersebut membuat manajemen perusahaan perlu melakukan perencanaan penjualan 
produk dengan baik, sehingga tercapai keuntungan dan pemenuhan pesanan. Salah satu parameter penting dalam perencanaan penjualan adalah jumlah produk yang akan diproduksi dan dijual untuk periode selanjutnya. Dalam melakukan prediksi atau peramalan penjualan produk atau permintaan konsumen bisa menggunakan beberapa metode peramalan seperti penelitian yang dilakukan oleh Karina dan Mariza di tahun 2019, dimana pada penelitian ini variabel data yang diamati adalah nilai penjualan, nama konsumen, tahun dan bulan yanh kemudian melakukan perbandingan peramalan penjualan dilakukan pengujian penerapan metode Naive dan Simple Moving Average menggunakan nilai akurasi MASE (Mean Absolute Square Error)[1].

Selanjutnya penelitian Yunus dkk di tahun 2018 melakukan analisis peramalan untuk memprediksi hasil produksi buah sawit pada PT. Bumi Sawit Sukses (BSS) menggunakan metode K-Nearest Neighbor dimana jumlah produksi kelapa sawit tidak menentu setiap bulannya. Penelitian ini bertujuan untuk periode yang akan datang pada PT.Bumi Sawit Sukses(BSS). Objek penelitian ini adalah jumlah produksi kelapa sawit sedangkan data yang digunakan merupakan data historis dari jumlah produksi tanaman kelapa sawit tahun 2015-2017. Dengan menggunakan metode (K - NN) K-Nearest Neighbor, Output dari Rapidminer didapatkan hasil akurasi $85,15 \%$, dapat dijadikan sebagai acuan untuk tahun selanjutnya agar perusahaan dapat mengambil keputusan yang tepat apabila produksi tanaman kelapa sawit mengalami penurunan dan perusahaan dapat terus meningkatkan hasil produksi kelapa sawit[2].

Selanjutnya di tahun 2014 Iman Mustofa dkk melakukan prediksi penjualan buku pada toko buku PT.Niaga Swadaya. Ia mengungkapkan bahwa dengan melihat berdasarkan data penjualan sebelumnya akan menghasilkan kemiripan data antara data penjualan di masa lalu dan di masa depan, hal tersebut dapat digunakan untuk memprediksi penjualan. Penjualan buku perlu diprediksi dengan akurat, karena hasil prediksi yang akurat sangat penting bagi perusahaan untuk asumsi yang digunakan dalam kegiatan perencanaan dan untuk pengembangan sistem kontrol keuangan jangka pendek [3].

Selanjutnya di tahun 2016 Resti Hutami dkk menyatakan bahwa Perusahaan yang didirikan dengan tujuan menghasilkan barang atau jasa yang ditujukan untuk memenuhi kebutuhan konsumen juga untuk memperoleh keuntungan bagi perusahaan tersebut. Perusahaan pasti mempunyai tujuan jangka panjang agar dimasa depan mengalami perubahan yang lebih baik dan berkembang dari sebelumnya. Dan salah satu kegiatan usaha yang harus dilakukan agar perusahaan tetap berjalan dan berkembang adalah penjualan. Keputusan yang diambil pemegang tanggung jawab perusahaan akan mempengaruhi perusahaan dimasa depan. Salah satu keputusan yang harus ditentukan yaitu produk yang akan diproduksi dan dijual untuk periode selanjutnya. Dalam menentukan keputusan diperlukan metode agar keputusan yang akan diambil dapat tepat sasaran. Teknik yang digunakan untuk memperkirakan keadaan pada periode selanjutnya disebut prediksi. Penelitian ini mengusulkan penggunaan metode KNearest Neighbor untuk melakukan prediksi data penjualan furniture pada CV. Octo Agung Jepara. Hasil penelitian menunjukan metode yang diusulkan berhasil diimplementasikan untuk menyelesaikan kasus prediksi penjualan dengan tingkat error atau MSE sebesar 6 persen dan akurasi 94 persen[4].

Selanjutnya ditahun 2018 Yulia Rizki melakukan peramalan pada PT.Bintang Multi Sarana Palembang. Ia menyatakan untuk mengetahui banyaknya permintaan konsumen akan produk elektronik berdasarkan data penjualan selama 3 tahun terakhir dibutuhkan prediksi untuk penjualan produk elektronik terlaris, guna untuk memudahkan pihak prusahaan dalam perencanaan penyediaan stok. Metode K-Nearest Neighbor yang dipilih karena berdasarkan penelitian dari nilai akurasi terhadap klasifikasi penjualan produk terlaris memiliki nilai sebesar $92,51 \%$ [5].

\subsection{Dasar Teori}

\subsubsection{K-Nearest Neighbor}

Algoritma k-nearest neighbor (K-NN atau KNN) adalah sebuah metode untuk melakukan klasifikasi terhadap objek berdasarkan data pembelajaran yang jaraknya paling dekat dengan objek tersebut. K-Nearest Neighbor berdasarkan konsep learning by analogy. Data learning di deskripsikan dengan atribut numerik $\mathrm{n}$-dimensi. Tiap data learning merepresentasikan sebuah titik, yang di tandai dengan $\mathrm{c}$, dalam ruang ndimensi. Jika sebuah data query yang labelnya tidak di ketahui diinputkan, maka KNearest Neighbor akan mencari $\mathrm{k}$ buah data learning yang jaraknya paling dekat dengan data query dalam ruang n-dimensi. Jarak antara data query dengan data learning dihitung dengan cara mengukur jarak antara titik yang merepresentasikan data query dengan semua titik yang merepresentasikan data learning dengan rumus Euclidean Distance berikut.

$$
\sqrt{(x 1-x 2)^{2}+(y 1-y 2)^{2} \ldots \ldots \ldots(2.1)}
$$

Pada fase training, algoritma ini hanya melakukan penyimpanan vektorvektor fitur dan klasifikasi data training sample. Pada fase klasifikasi, fitur - fitur yang sama dihitung untuk testing data (klasifikasinya belum di ketahui). Jarak dari vektor yang baru ini terhadap seluruh vektor training sample di hitung, dan sejumlah $\mathrm{k}$ buah yang paling dekat diambil. Titik yang baru klasifikasinya di prediksikan termasuk pada klasifikasi terbanyak dari titik-titik tersebut. Nilai $\mathrm{k}$ yang terbaik untuk algoritma ini 
tergantung pada data; secara umumnya, nilai $\mathrm{k}$ yang tinggi akan mengurangi efek noise pada klasifikasi, tetapi membuat batasan antara setiap klasifikasi menjadi lebih kabur. Nilai k yang bagus dapat di pilih dengan optimasi parameter, misalnya dengan menggunakan cross-validation. Kasus khusus di mana klasifikasi di prediksikan berdasarkan data pembelajaran yang paling dekat (dengan kata lain, $\mathrm{k}$ $=1$ ) disebut algoritma nearest neighbor.

$\mathrm{K}$ buah data learning terdekat akan melakukan voting untuk menentukan label mayoritas. Label data query akan ditentukan berdasarkan label mayoritas dan jika ada lebih dari satu label mayoritas maka label data query dapat di pilih secara acak di antara label-label mayoritas yang ada[6].

\section{METODE PENELITIAN}

\subsection{Desain Arsitektur}

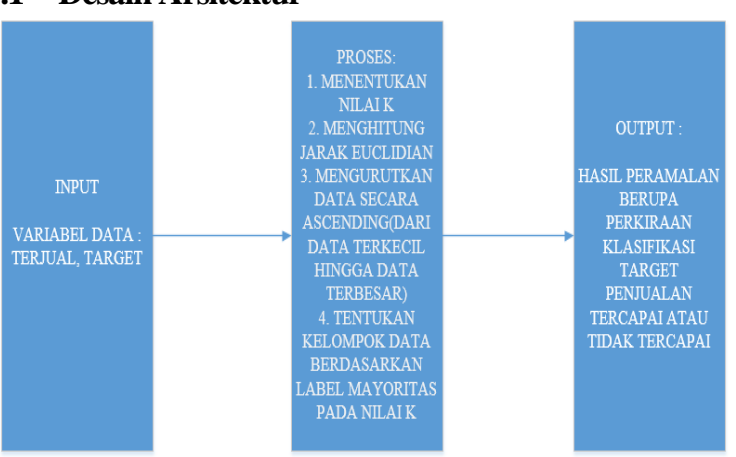

Gambar 1 Desain Arsitektur

Gambar 1 menunjukan sistem memiliki 3 langkah, yaitu input, proses, dan output. Input yaitu memasukkan variable harga \& jumlah terjual, Proses yaitu melakukan perhitungan nilai dari penentuan nilai $\mathrm{K}$ sampai perhitungan peramalan, dan pada output yaitu hasil dari proses perhitungan tersebut.

\subsection{DFD Level 0}

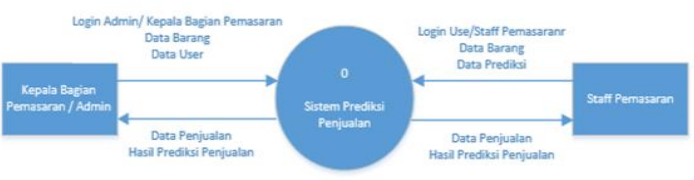

Gambar 2 DFD Level 0

Gambar 1 menunjukan DFD Level 0 terdapat 2 hak akses yaitu Adminstrator dan User. Adminstrator dapat mengakses fitur data barang, data prediksi, data user dan dapat melihat hasil klasifikasi prediksi dari proses perhitungan. Sedangkan User hanya dapat mengakses data barang, data prediksi dan hasil klasifikasi prediksi dari proses perhitungan.

\subsection{DFD Level 1}

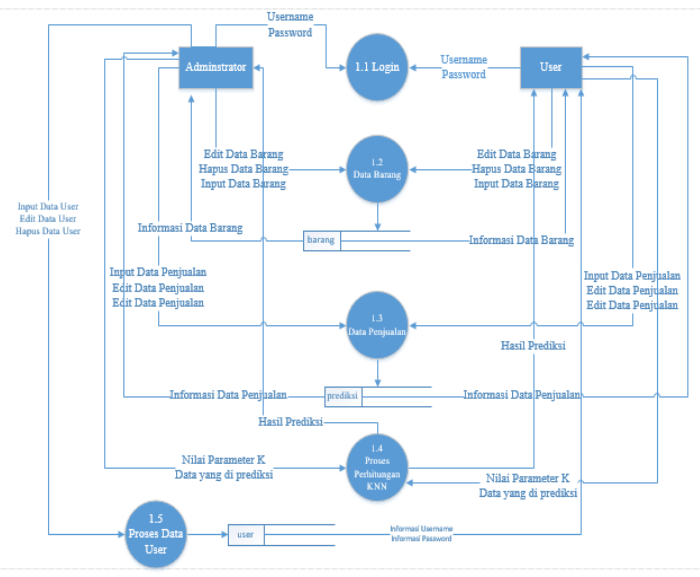

Gambar 3 DFD Level 1

Gambar 2 menunjukan DFD Level 1, terdapat 5 proses yaitu proses login kedalam sitem menggunakan hak akses yang dimiliki, setelah login terdapat beberapa menu yaitu menu data barang, menu data penjualan, menu data user, dan proses prediksi menggunakan perhitungan $K$-Nearest Neighbor.

\subsection{Flowchart Sistem}

Flowchart sistem ini menjelaskan proses berjalananya aplikasi seperti ditunjukkan pada Gambar 3.

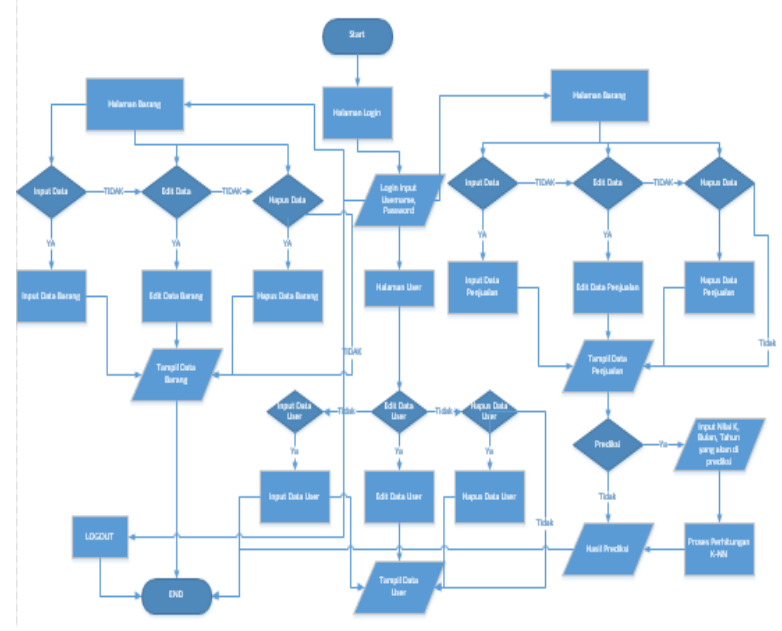

Gambar 4 Flowchart Sistem

Berdasarkan flowchart pada Gambar 3, alur kerja sistem dimulai dari halaman login, kemudian user diminta untuk menginputkan username dan password agar bisa masuk kehalaman utama sistem. Setelah login terdapat 4 menu yaitu menu barang, menu prediksi, menu user dan menu logout. Pada menu pertama yaitu menu barang akan menampilkan data barang, terdapat 3 proses yaitu tambah data, edit data, dan hapus data barang. Pada menu kedua yaitu menu prediksi akan menampilkan data penjualan, pada menu ini terdapat 4 proses yaitu input,edit, hapus data dan proses prediksi dengan prehitungan 
metode K-NN. Pada proses perhitungan, pengguna diminta untuk menginputkan nilai parameter $\mathrm{K}$ dan data penjualan yang akan di prediksi kemudian hasil prediksi akan muncul berupa klasifikasi penjualan naik atau turun. Ada menu user, pada menu ini pengguna dapat melakukan proses input,edit, delete data user. Data user ini yang digunakan untuk login pada saat sistem dijalankan. Kemudian menu terakhir menu logout, menu ini digunakan untuk keluar dari sistem.

\subsection{Contoh Perhitungan}

Tabel 1 Contoh Data Uji

\begin{tabular}{|c|c|c|}
\hline Terjual & Target & Klasifikasi \\
\hline 100 & 250 & Tidak Tercapai \\
\hline 61 & 200 & Tidak Tercapai \\
\hline 100 & 100 & Tercapai \\
\hline 246 & 200 & Tercapai \\
\hline 128 & 100 & Tercapai \\
\hline
\end{tabular}

Pada tabel 1 ditampilkan contoh data latih yang akan digunakan sebagai pembanding dengan data uji yang memiliki nilai $\mathrm{x} 1=100, \mathrm{x} 2=200$, dan nilai $\mathrm{K}=3$.

Dengan menggunakan rumus jarak euclidian maka diperoleh hasil yang ada pada tabel 2 :

Tabel 2 Hasil Perhitungan Manual

\begin{tabular}{|l|l|l|l|l|}
\hline Terjual & Target & Klasifikasi & Jarak & Ranking \\
\hline 100 & 250 & $\begin{array}{l}\text { Tidak } \\
\text { Tercapai }\end{array}$ & 50 & 2 \\
\hline 61 & 200 & $\begin{array}{l}\text { Tidak } \\
\text { Tercapai }\end{array}$ & 39 & 1 \\
\hline 100 & 100 & Tercapai & 100 & 3 \\
\hline 246 & 200 & Tercapai & 146 & 5 \\
\hline 128 & 100 & Tercapai & 103,8460 & 4 \\
\hline
\end{tabular}

Setelah diperoleh nilai jarak data uji dengan masingmasing data latih yang ada kemudian diambil nilai terkecil sesuai jumlah nilai $\mathrm{K}$ yang sudah ditentukan, karena nilai $\mathrm{K}$ yang ditentukan adalah 3 , maka hanya 3 nilai terkecil saja yang diambil. Kemudian diambil mayoritas klasifikasi terbanyak dari 3 data terkecil tersebut. Terdapat 2 klasifikasi tidak tercapai dan 1 klasifikasi tercepai sehingga hasil dari perhitungan menyimpulkan bahwa klasifikasi untuk data uji $\mathrm{x} 1=$ 100 , x2 = 200, dan nilai $\mathrm{K}=3$ tidak tercapai.

\section{HASIL DAN PEMBAHASAN \\ 4.1 Tampilan Menu Barang dan CRUD}

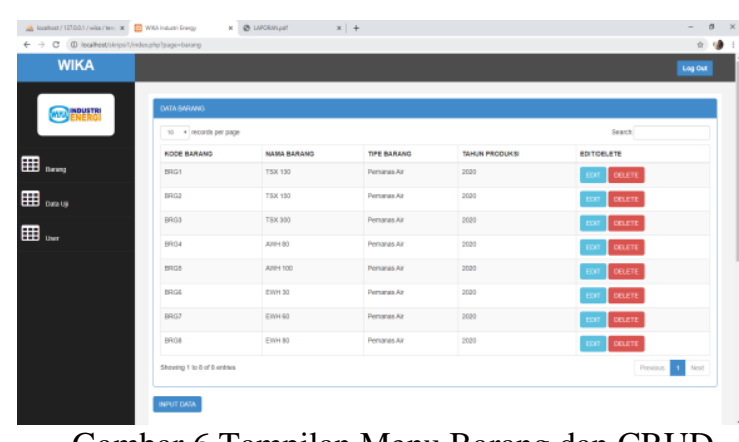

Gambar 6 Tampilan Menu Barang dan CRUD

Gamber 6 menunjukan tampilan halaman menu barang. Pada menu barang ditampilkan seluruh data barang yang ada berupa tabel. Terdapat 3 tombol yaitu tombol input, edit \& delete yang masing-masing berfungsi untuk meruba data, menghapus data, dan menyimpan data baru.

\subsection{Tampilan Form Edit}

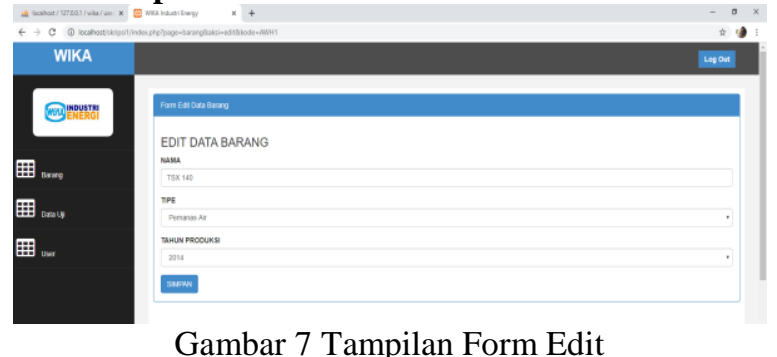

Pada gambar 7 ditampilkan desain form edit yang berfungsi untuk merubah data apabila terjadi kesalahan pada saat menginputkan data.

\subsection{Tampilan Form Input}

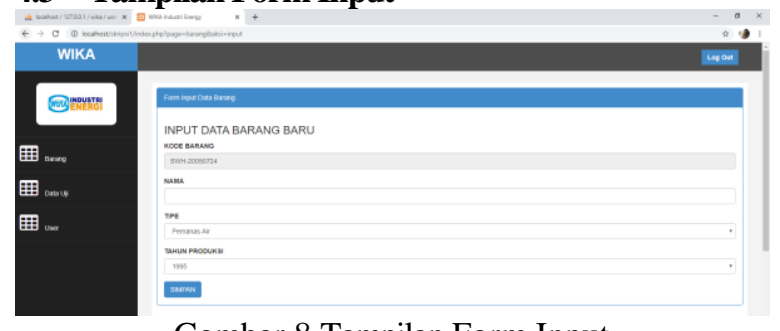

Gambar 8 Tampilan Form Input

Pada gambar 8 merupakan tampilan form input data yang berfungsi untuk menambahkan data baru.

\subsection{Tampilan Form Menu Data Uji}

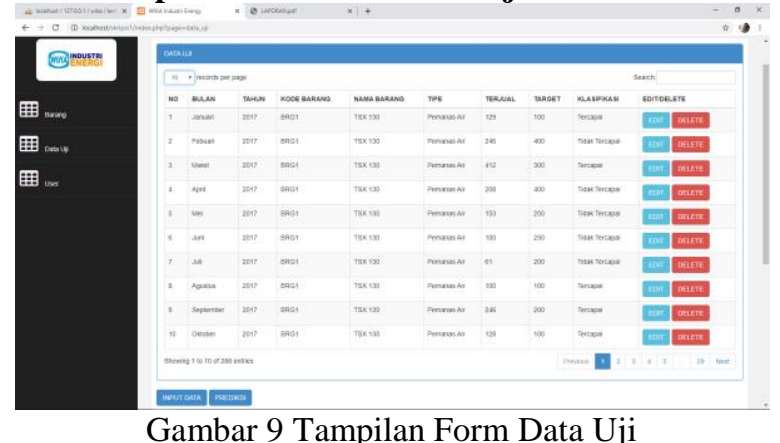

Gambar 9 Tampilan Form Data Uji 
Pada gambar 9 ditampilkan menu data uji , pada menu ini terdapat sebuah tombol yang dapat digunakan untuk masuk pada form input data yang akan diprediksi.

\subsection{Tampilan Form Input Data Prediksi}

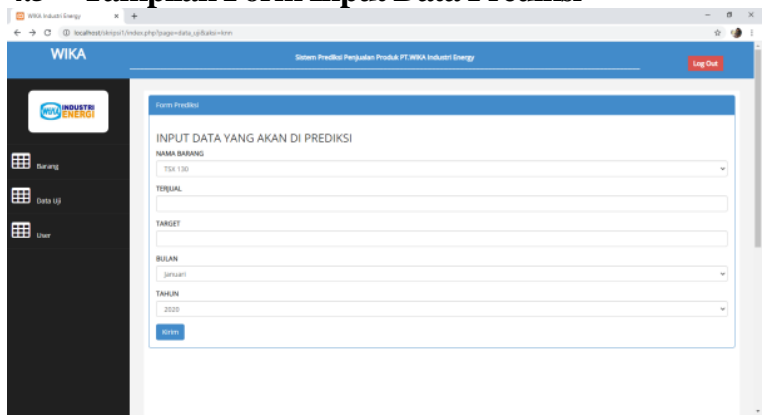

Gambar 10 Tampilan Form Input Data Prediksi Pada gambar 10 merupakan tampilan form input data yang akan diprediksi. Pada form ini user diminta untuk memasukan data yang akan diuji.

\subsection{Tampilan Hasil Prediksi}

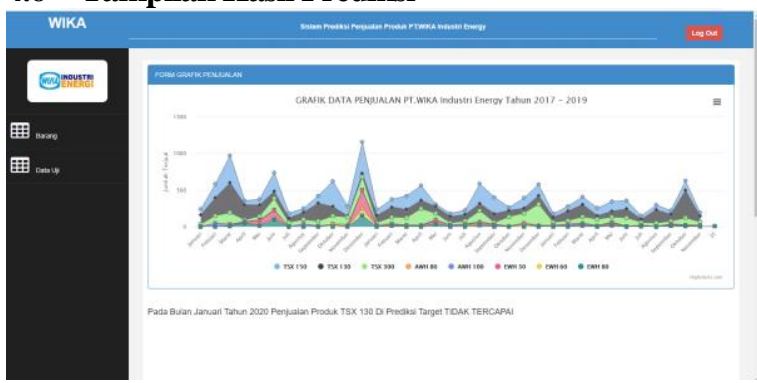

Gambar 11 Tampilan Hasil Prediksi Halaman User

Gambar 11 merupakan tampilan hasil prediksi ketika pengguna login menggunakan hak akes sebagai user biasa. Pada halaman hasil prediksi ditampilkan grafik penjualan dan hasil prediksi berupa klasifikasi dari data yang di inputkan oleh pengguna pada halaman input data prediksi.
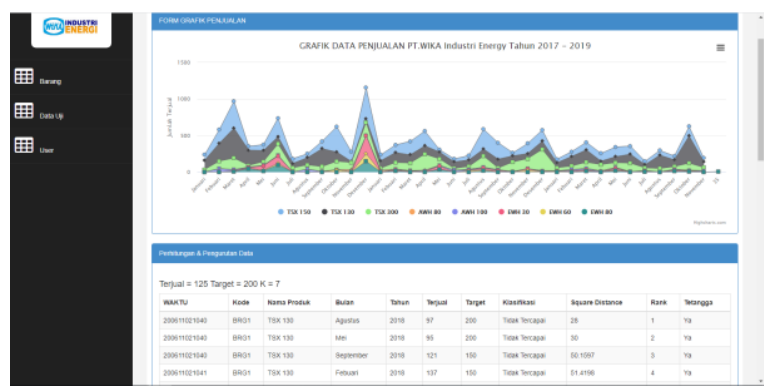

Gambar 12 Tampilan Hasil Prediksi Halaman Admin

Gambar 12 adalah tampilan hasil prediksi ketika pengguna login menggunakan hak akses sebagai adminstrator. Pada halaman ini menampilkan grafik penjualan, hasil prediksi dan hasil perhitungan menggunakan metode $K$-Nearest Neighbor.

\subsection{Pengujian Akurasi Metode}

Dengan menggunakan 288 data training dan 20 data test, data pada tahun 2017-2019 diperoleh hasil yang dapat dilihat pada tabel 3 .

Tabel 3 Pengujian Akurasi Metode

\begin{tabular}{|c|c|c|c|c|c|c|c|c|}
\hline \multirow{2}{*}{ No } & \multirow{2}{*}{ Nama } & \multicolumn{3}{|c|}{ Data Asli } & \multicolumn{3}{|c|}{ Hasil Prediksi Program } & \multirow{2}{*}{ Keterangan } \\
\hline & & Terjual & Target & Klasifikasi & Target & Terjual & Klasifikasi & \\
\hline 1 & TSX 130 & 48 & 40 & Tercapai & 48 & 40 & Tidak Tercapai & Tidak Sama \\
\hline 2 & TSX 150 & 102 & 100 & Tercapai & 102 & 100 & Tercapai & Sama \\
\hline 3 & TSX 300 & 40 & 80 & Tidak Tercapai & 40 & 80 & Tidak Tercapai & Sama \\
\hline 4 & AWH 80 & 25 & 10 & Tercapai & 25 & 10 & Tercapai & Sama \\
\hline 5 & AWH 100 & 50 & 25 & Tercapai & 50 & 25 & Tercapai & Sama \\
\hline 6 & EWH 30 & 10 & 10 & Tercapai & 10 & 10 & Tercapai & Sama \\
\hline 7 & EWH 60 & 12 & 10 & Tercapai & 12 & 10 & Tercapai & Sama \\
\hline 8 & EWH 80 & 15 & 10 & Tercapai & 15 & 10 & Tercapai & Sama \\
\hline 9 & TSX 130 & 50 & 50 & Tercapai & 50 & 50 & Tercapai & Sama \\
\hline 10 & TSX 150 & 80 & 100 & Tidak Tercapai & 80 & 100 & Tidak Tercapai & Sama \\
\hline 11 & TSX 300 & 40 & 50 & Tidak Tercacpai & 40 & 50 & Tidak Tercapai & Sama \\
\hline 12 & AWH 80 & 120 & 100 & Tercapai & 120 & 100 & Tercapai & Sama \\
\hline 13 & AWH 100 & 50 & 40 & Tercapai & 50 & 40 & Tercapai & Sama \\
\hline 14 & EWH 30 & 8 & 10 & Tidak Tercapai & 8 & 10 & Tidak Tercapai & Sama \\
\hline 15 & EWH 60 & 20 & 10 & Tercapai & 20 & 10 & Tercapai & Sama \\
\hline 16 & EWH 80 & 25 & 10 & Tercapai & 25 & 10 & Tercapai & Sama \\
\hline 17 & TSX 130 & 115 & 100 & Tercapai & 115 & 100 & Tercapai & Sama \\
\hline 18 & TSX 150 & 85 & 90 & Tidak Tercapai & 85 & 90 & Tidak Tercapai & Sama \\
\hline 19 & TSX 300 & 80 & 100 & Tidak Tercapai & 80 & 100 & Tidak Tercapai & Sama \\
\hline 20 & AWH 100 & 60 & 50 & Tercapai & 60 & 50 & Tercapai & Sama \\
\hline
\end{tabular}

Keterangan :

Tabel 3 adalah hasil pengujian perhitungan seluruh data yang ada dengan 20 data uji dari produk yang ada. Perhitungan yang dibandingkan adalah hasil perhitungan manual dengan hasil perhitungan program. Berdasarkan tabel 3 dengan menggunakan rumus persentase $=(($ Total Data Yang Sama $) /($ Total Data))x 100\% diperoleh hasil akurasi $95 \%$ dan nilai error $5 \%$.

\section{KESIMPULAN DAN SARAN \\ 5.1 Kesimpulan}

Berdasarkan beberapa pengujian yang telah dilakukan dapat disimpulkan :

1. Dari hasil pengujian fungsional pengujian program, fitur-fitur pengelolaan data (simpan, edit hapus data dan report) pada sistem menunjukan hasil fitur berjalan tanpa ada erorr.

2. Hasil Pengujian akurasi metode menggunakan 8 data latih diperoleh hasil nilai akurasi $95 \%$ dan nilai error sebesar $5 \%$.

\subsection{Saran}

Berdasarkan penelitian yang telah dilakukan, maka penulis dapat memberikan saran-saran untuk pengembangan selanjutnya antar lain :

1. Sistem dapat ditambahkan fitur berupa notifikasi yang dikirimkan pada adminstrator apabila ada user yang masuk kedalam sistem.

2. Pada penelitian penerapan metode K-Nearest Neighbor untuk prediksi penjualan berbasis web pada PT.WIKA Industri Energy, dapat dikembangkan menggunakan metode lain seperti Fuzzy, Time Series, Least Square dan lain-lain. 
3. Untuk pengembangkan pada sistem ini kedepannya disrankan menggunakan lebih banyak data agar hasil semakin akurat.

\section{DAFTAR PUSTAKA}

[1] Auliasari, K. dan Kertaningtyas, M.., 2019. Penerapan Metode Peramalan untuk Identifikasi Potensi Permintaan Konsumen. INFORMAL INFORMATICS JOURNAL Universitas Negeri Jember, Vol. 4 No. 3, pp. 121-129.

[2] Yunus, A., Akbar, M. dan Andri, A., 2019, January. Data Mining Untuk Memprediksi Hasil Produksi Buah Sawit Pada Pt Bumi Sawit Sukses (BSS) Menggunakan Metode K-Nearest Neighbor. (Vol. 1, No. 1, pp. 198-207).

[3] Kamal, I.M. dan Ilyas, R., 2017. PREDIKSI PENJUALAN BUKU MENGGUNAKAN
DATA MINING DI PT. NIAGA SWADAYA. SEMNASTEKNOMEDIA ONLINE

[4] HUTAMI, R., IMPLEMENTASI METODE KNEAREST NEIGHBOR UNTUK PREDIKSI PENJUALAN FURNITURE PADA CV. OCTO AGUNG JEPARA.

[5] AMALIA, Y.R., 2018. PENERAPAN DATA MINING UNTUK PREDIKSI PENJUALAN PRODUK ELEKTRONIK TERLARIS MENGGUNAKAN METODE K-NEAREST NEIGHBOR (Studi Kasus: PT. Bintang Multi Sarana Palembang) (Doctoral dissertation, UIN RADEN FATAH PALEMBANG).

[6] PENERAPAN METODE K-NEAREST NEIGHBORS UNTUK PREDIKSI PENJUALAN BERBASIS WEB PADA BOUTIQ DEALOVE BONDOWOSO 